\title{
PENGARUH MODEL PROBLEM BASED LEARNING TERHADAP KOMPETENSI PENGETAHUAN DAN KETRAMPILAN BERPIKIR KRITIS SISWA MADRASAH ALIYAH BPD IHA TENTANG KONFLIK
}

\author{
Yosepus A. Hallatu \\ Pascasarjana Universitas Negeri Surabaya \\ E-mail: yossihallatu86@gmail.com \\ Pembimbing \\ Dr. Ketut Prasetyo, M.S \\ Dosen Pascasarjana Universitas Negeri Surabaya \\ E-mail: ketutprasetyo1205@gmail.com \\ Prof. Dr. Ali Haidar \\ Dosen Pascasarjana Universitas Negeri Surabaya \\ E-mail:m.alihaidar@ymail.com \\ ABSTRAK
}

Penelitian ini bertujuan untuk mengetahui pengaruh mod 1 probsm based learning terhadap kompetensi pengetahuan dan ketrampilan berpikir kriss iswa tentang konflik antar desa. Penelitian ini menggunakan rancangan penelitian soerime/dengan menggunakan teknik pretest-postest randomized control design dengan populasi penelitian adalah seluruh kelas XI pada Madrasah Aliyah BPD (Badan Pengelola Desa) Ib a Provinsi Maluku yang terdiri dari tiga kelas. Sedangkan sampel penelitian ter Irry dari dua kelas, yaitu XI 2 sebagai kelas eksperimen yang menerapkan model problem ased learning dan XI 3 sebagai kelas kontrol yang menerapkan model pembelaja an jngskng. Analisis data kompetensi pengetahuan

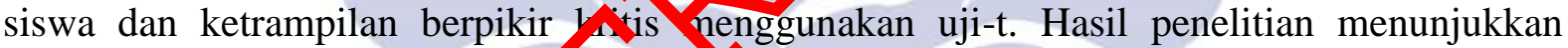
bahwa analisis deskriptif mode problembased learning berpengaruh untuk meningkatkan kompetensi pengetahuan dan ketramp $1 \mathrm{~m}$ berpikir kritis siswa yang didasarkan pada beberapa hal, yaitu: (1) aktivitas si wa tergolong aktif, (2) ketuntasan hasil belajar tercapai. Hal ini ditunjukkan oleh nilai sig $0,00<0,05$ dan $t_{\text {hitung }}(5,637) \geq t_{\text {tabel }}(1,688)$. Hal ini berarti bahwa ada perbedaan rata ata post est siswa pada model problem based learning lebih baik dibandingkan mode pembelajaran langsung dalam hal meningkatkan kompetensi pengetahuan dan ketram 1 an berpikir kritis.

Kata Kunci: problem based learning, kompetensi pengetahuan, berpikir kritis dan konflik.

\begin{abstract}
This study aimed is to determine the effect of problem based learning model of the competence of knowledge and critical thinking skills of students about the conflict between the villages. This study uses experimental research design. The techniques of pretestposttest randomized control design is used in this study. The population was the whole of the class XI at Madrasah Aliyah BPD (board of villages organizer) Iha in Maluku Province which consists of three classes. While the sample consisted of two classes, namely XI 2 as an experimental class that implements the model problem based learning and XI 3 as the control class that implements direct instructional model. The t-test is used to analize the data. The results showed that the descriptive analysis model of problem based learning effect to
\end{abstract}


enhance the competence of knowledge and critical thinking skills of students based on several things, namely: (1) the students activity is categorized actif, (2) completeness of the learning outcomes achieved. This is indicated by sig $0,000 \leq 0.05$ and the $t$ calculated (5.637) $\geq t$ table (1.688). This means that there are differences in the average post-test students on the model of problem based learning is better than direct learning model in terms of improving the knowledge and competence of critical thinking skills.

Keywords: problem based learning, knowledge competencies, critical thinking, conflict.

\section{PENDAHULUAN}

Pembelajaran pada dasarnya merupakan proses yang diselenggarakan oleh guru untuk membelajarkan siswa dalam belajar demi memperoleh dan memproses pengetahuan, ketrampilan dan sikap siswa tersebut. Pembelajaran seorang peserta didik adalah fungsi perbandingan waktu dengan waktu sebenarnya yang diperlukan sebenarnya yang digunakan untuk belajar

mengkaitkan bahan pelajaran yang dipelajarinya dengan kehidupan nyata dalam lingkungannya. Pembelajaran yang hanya berpusat pada guru tersebut menjadikan kegiatr 1 Dolajar menjadi tidak bermakna dan tentu ya akan berpengaruh pada hasil be ai da daya berpikir siswa.

Hasil se ajar ya optimal pada dasarnya di iginkan géh semua pihak dan wawasan berpikir yang logis dan kritis sangat untuk mempelajari sesuatu tema kibutuhkan demi perkembangan kemajuan pembelajaran. $\quad$ Kedepan. Selain itu, dalam penerapan Kesuksesan pembelajaran tuntas te fantung model pembelajaran jarang sekali kepada kriteria tertentu inidis du peserta didik, pengajaran guru, dan lingkungan. Kriteria itu mencaky petekwan, waktu untuk belajar, kadar ombélajaran, mutu kegiatan pembelajaran, kemampuan memahami petunjuk kegiatan, dan lingkungan pembentuk.

Kenyataannya, dalam kondisi pembelajaran masih terdapat indikasi guru dalam melaksanakan kegiatan pembelajaran masih secara kontekstual. Guru menyampaikan materi pelajaran dengan metode ceramah, sehingga menyebabkan siswa menjadi pasif, membosankan dan siswa tidak bisa menggunakan model pembelajaran yang mampu membangkitkan aktivitas belajar siswa, kecenderungan yang dilakukan adalah penerapan model pembelajaran konvensional -sehingga pembelajaranpun berjalan secara monoton.

Guru dalam proses belajar mengajar sebaiknya memilih model pembelajaran yang tepat agar peserta didik dapat secara aktif terlibat dalam proses pembelajaran. Pembelajaran yang baik akan mampu menghasilkan kualitas siswa yang baik. Pembelajaran yang baik adalah pembelajaran yang berpusat pada siswa 
(student centered) sehingga siswa akan memiliki pengalaman langsung dalam belajar. Dalam perkembangannya, banyak faktor yang dapat mempengaruhi hasil pembelajaran dan tingkat berpikir siswa. Ada faktor yang dapat diubah (seperti cara mengajar, mutu rancangan, model evaluasi, dan lain-lain), adapula faktor yang harus diterima apa adanya (seperti: latar belakang siswa, gaji, lingkungan sekolah, dan lainlain).

Kenyataan konflik dan pengaruhnya terhadap lingkungan serta proses belajar mengajar dan perkembangan pendidikan yang terjadi salah satunya dapat dilihat pada desa Iha Kecamatan Huamual Kabupaten Seram Bagian Barat Provinsi Maluku. Dimana, akibat konflik antardesa Iha dan Luhu yang terjadi pada tahun 2009 2011 dan 2014 hingga sekara g mas b memberikan pengaruh dan dampak rang sangat signifikan bagk ork mbangan pendidikan anak-an ak di desa Iha dan kinerja guru dalam proses belajar mengajar hingga pencapaian hasil belajar siswa di sekolah. Dengan kondisi konflik yang terjadi mengakibatkan lingkungan yang membentuk siswa dalam aktivitas kesehariannya sangat tidak ideal bagi proses pembelajaran, infrastruktur sekolah terbatas, minimnya tenaga pengajar dan kurangnya invoasi cara mengajar guru.

Kondisi konflik yang terjadi sangat dirasakan oleh siswa Madrasah Aliyah
BPD (Badan Pengelola Desa) Iha

Kecamatan Huamual Kabupaten Seram Bagian Barat Provinsi Maluku. Berdasarkan hasil observasi, aktivitas mengajar yang dilakukan guru di Madrasah Aliyah BPD (Badan Pengelola Desa) Iha masih belum maksimal. Guru yang mengajar masih secara kontekstual, tidak mengkaitkan materi pembelajaran dengan kehidupan nyata, dan belum menggunakan pendekatan saintifik. Upaya mengatasi permasalahan ya $\mathrm{g}$ te jadi pada siswa Madrasah Al yan Bro/(Badan Pengelola Desa) IhrKec matan Huamual Kabupaten Seram B gian Barat Provinsi Maluku t rsebut salah satunya dengan menerapkan model roblem based learning.

Peigajaran model problem based learning merupakan suatu pendekatan pembelajaran dimana siswa mengerjakan permasalahan yang otentik dengan maksud untuk menyusun pengetahuan mereka sendiri, mengembangkan inkuiri dan mengembangkan ketrampilan berpikir tingkat tinggi, 0 serta mengembangkan kemandirian dan percaya diri (Arends, 2008).

Kondisi konflik dan proses pembelajaran yang terjadi, ada beberapa alasan kenapa memilih model problem based learning untuk diterapkan di Madrasah Aliyah BPD (Badan Pengelola Desa) Iha Kecamatan Huamual Kabupaten Seram Bagian Barat Provinsi Maluku karena model problem 
based learning belum pernah diterapkan dalam proses pembelajaran di Madrasah Aliyah BPD (Badan Pengelola Desa) Iha Kecamatan Huamual Kabupaten Seram Bagian Barat Provinsi Maluku; model problem based learning merupakan model pembelajaran yang berpusat pada peserta didik (student centered).

Tujuan dari penelitian ini adalah untuk menganalisis pengaruh model problem

\section{METODE PENELITIAN}

Jenis penelitian ini menggunakan penelitian eksperimen. Penelitian ini dilakukan dengan membandingkan efek perlakuan pembelajaran yang berbeda, yaitu dengan menggunakan kelas eksperimen yang mendapat perlakuan dengan model problem based learning dan kelas kontrol van, mendapat perlakuan dengar moay pembelajaran langsung. Rancangan yang digunakan dalam penemiar inj adalah pretest-posttest rand omi ed cuntrol design (Sugiyono, 2012:12).

Rancangan ini dilakukan pre-test sebelum perlakuan dan post-test setelah perlakuan untuk mengetahui pengaruh model pembelajaran terhadap kompetensi pengetahuan dan ketrampilan berpikir kritis dengan perlakuan tersebut.

Penelitian ini menggunakan variabel bebas yang mempengaruhi atau yang menjadi sebab timbulnya variabel terikat. Variabel bebas dalam penelitian ini adalah model based learning terhadap kemampuan berpikir kritis siswa; untuk mendeskripsikan aktivitas siswa selama pembelajaran melalui penerapan model problem based learning; untuk mendeskripsikan respon siswa terhadap penerapan model problem based learning pada materi konflik sosial terhadap konflik yang terjadi.

problem based Larning, variabel terikat yang dipeng aruhi ato menjadi akibat karena vany. varabel bebas. Variabel terika dalam penelitian ini adalah kompetensi pengetahuan siswa setelah diveri perlakuan dengan pembelajaran m:del problem based learning, dan variabel kontrol yang dikendalikan atau dibuat konstan sehingga hubungan variabel bebas terhadap variabel terikat tidak dopengaruhi oleh faktor luar yang tidak diteliti. Variabel terikat dalam penelitian ini adalah ketrampilan berpikir kritis siswa.

Populasi dalam penelitian ini adalah seluruh siswa kelas XI Madrasah Aliyah Badan Pengelola Desa (BPD) Iha semester genap tahun pelajaran 2016/2017, yang terdiri dari tiga kelas yaitu kelas XI 1 - XI 3. Sedangkan sampel pada penelitian ini adalah 2 kelas yang homogen.

Homogenitas kelompok yang digunakan ditentukan menggunakan ulangan harian siswa. Selanjutnya dipilih dua kelas yang 
ditetapkan kelas XI 2 sebagai kelompok eksperimen (kelas dengan perlakuan model problem based learning) dan kelas XI 3 sebagai kelompok kontrol (kelas dengan perlakuan model pembelajaran langsung.

Data yang digunakan dalam penelitian ini dikumpulkan dengan beberapa cara yaitu (1) pemberian tes (pre-test yang dilakukan pada awal pembelajaran) untuk mengetahui homogenitas siswa sebelum mempelajari materi sesungguhnya yaitu materi konflik sosial, dan (post-test yang dilakukan sesudah pembelajaran) untuk mengetahui seberapa besar kompetensi pengetahuan siswa yang akan mengontrol ketrampilan berpikir kritis siswa dalam menguasai materi konflik sosial, (2) rubrik penilaian berpikir kritis siswa yang disusun berdasrkan indikator berpikir kriti (3) observasi yang dilakukan dengan menggunakan LKS (Lemhar Ke jatan Siswa) untuk mengarahk n sis a dalam pengambilan data di lapa gan terkait dengan konflik sosia yang terjadi, (4) angket yang digunakan |Tuntuk mengumpulkan mengamati proses diskusi siswa selama pembelajaran model problem based learning diterapkan.

Sumber pengumpulan data sebelum digunakan, instrumen pengumpulan data terlebih dulu divalidasi oleh dua orang ahli dan dilanjutkan dengan diujicobakan kepada siswa yang tidak menjadi sampel dalam penelitian. Perhitungan validitas tiap butir digunakan analisis butir, yakni mengkorelasikan skor tiap butir dengan skor total yang merupakan jumlah tiap skor butir dengan melakukan uji validitas butir.

Penelitian ini juga melakukan uji normalitas untuk menguji data yang diperoleh terdistribusi normal atau tidak dengan menggunakan uji kolmogorofsmirnov (two sample), dengan dasar keputusan nilai signifikansi atau probalitas $>0,05$, maka distribusi adalah normal dan uji homogenitas untuk menguji sampel yang diambi berasa ari populasi yang homogen atau fida / dengan menggunakan uji Kesanaan varians (Levene's test), dengan dasar keputusan nilai signifikansi atounobalitas $>0,05$, maka varians tiap ke 3mpok homogen yang dilakukan menggunakan SPSS 19.0 for windows.

Analisis data yang digunakan dalam penelitian berorientasi pada analisis kompetensi pengetahuan siswa setelah mengikuti pembelajaran dengan model problem based learning yang dilihat dari hasil tes siswa berdasarkan rubrik skor berpikir kritis dan dihitung dengan cara penskoran per indikator berpikir kritis dalam tes dan penskoran berpikir kritis siswa secara klasikal; analisis ketrampilan berpikir kritis siswa dengan mengamati cara berpikir kritis siswa selama proses pembelajaran yang diamati oleh dua orang pengamat dengan menggunakan angket ketrampilan berpikir kritis siswa, yang 
dimana tercapainya keefektivan berpikir kritis siswa jika semua aspek terpenuhi dengan kategori baik; uji hipotesis menggunakan uji-t untuk menguji signifikansi beda rata-rata dua kelompok dalam membuktikan kompetensis pengetahuan dan ketrampilan berpikir kritis siswa yang menerapkan model problem based learning dengan model pembelajaran langsung. Dasar pengambilan keputusan

\section{HASIL DAN PEMBAHASAN}

Pembahasan hasil penelitian ini berdasarkan pada faktor-faktor yang diamati dan ditemukan dalam penelitian.

\section{A. Analisis \\ Data \\ Kompetensi}

\section{Pengetahuan Siswa Berdasarkan}

Indikator Berpikir Kritis

Penilaian terhadap peserta didik ntu semua mata pelajaran, kompetens inti yan harus dimiliki oleh peserta divik pada rmah pengetahuan adalak $\lambda$ nemahami pengetahuan (faktral, kons-ptual, dan

Tabel 1. Kompetensi Pengetahuan Berdasarkan Indikator Berpikir Kritis

\begin{tabular}{|c|c|c|c|}
\hline $\begin{array}{l}\text { Indikator Dimensi } \\
\text { Pengetahuan }\end{array}$ & $\begin{array}{c}\text { Indikator } \\
\text { Berpikir Kritis }\end{array}$ & Sub Indikator Berpikir Kritis & $\begin{array}{l}\text { Dimensi } \\
\text { Proses } \\
\text { Kognitif }\end{array}$ \\
\hline \multirow[t]{4}{*}{ Faktual } & \multirow{4}{*}{$\begin{array}{l}\text { Memberikan } \\
\text { penjelasan } \\
\text { sederhana. }\end{array}$} & \multirow{2}{*}{$\begin{array}{ll}\text { a. } & \text { Memfokuskan } \\
\text { pertanyaan. }\end{array}$} & $\mathrm{C} 1$ \\
\hline & & & $\mathrm{C} 1$ \\
\hline & & \multirow[t]{2}{*}{ b. Menganalisis argumen. } & $\mathrm{C} 2$ \\
\hline & & & $\mathrm{C} 2$ \\
\hline Konseptual & $\begin{array}{l}\text { Membangun } \\
\text { ketrampilan } \\
\text { dasar. }\end{array}$ & $\begin{array}{l}\text { Mengobservasi dan } \\
\text { mempertimbangkan hasil } \\
\text { observasi. }\end{array}$ & $\mathrm{C} 3$ \\
\hline \multirow[t]{5}{*}{ Prosedural } & \multirow{5}{*}{$\begin{array}{l}\text { Membuat } \\
\text { kesimpulan. }\end{array}$} & \multirow{2}{*}{$\begin{array}{l}\text { a. Melakukan dan } \\
\text { mempertimbangkan hasil } \\
\text { induksi dan deduksi. }\end{array}$} & $\mathrm{C} 3$ \\
\hline & & & $\mathrm{C} 4$ \\
\hline & & \multirow{3}{*}{$\begin{array}{l}\text { b. Membuat dan } \\
\text { mempertimbangkan hasil } \\
\text { keputusan. }\end{array}$} & $\mathrm{C} 4$ \\
\hline & & & $\mathrm{C} 5$ \\
\hline & & & C6 \\
\hline
\end{tabular}


1. Deskripsi Hasil Kompetensi pembelajaran materi konflik sosial dengan Pengetahuan Siswa per Indikator model problem based learning (kelas

\section{Berpikir Kritis}

Hasil kompetensi pengetahuan siswa per indikator berpikir kritis dilihat pada posttest yang dikerjakan oleh siswa menunjukan bahwa terjadi peningkatan kompetensi pengetahuan siswa pada

Tabel 2. Perbandingan Presentase Hasil Kompetensi Pengetahuan Siswa per Indikator Berpikir Kritis Pada Kelas Eksperimen dan Kelas Kontrol

\begin{tabular}{|l|c|c|c|c|}
\hline \multirow{2}{*}{ Sub Indikator } & \multicolumn{2}{|c|}{ Kelas Eksperimen } & \multicolumn{2}{c|}{ Kelas Kontrol } \\
\cline { 2 - 5 } & Presentase & Kriteria & Presentase & Kriteria \\
\hline $\begin{array}{l}\text { Memberikan Penjelasan } \\
\text { Sedrhana }\end{array}$ & $89,5 \%$ & $\begin{array}{l}\text { Sangat } \\
\text { Tinggi }\end{array}$ & 55,80 & Rendah \\
\hline $\begin{array}{l}\text { Membangun Ketrampilan } \\
\text { Dasar }\end{array}$ & $97 \%$ & $\begin{array}{l}\text { Sangat } \\
\text { Tinggi }\end{array}$ & Sedang \\
\hline Membuat Kesimpulan & $84 \%$ & Tinggi & $37, \%$ & $\begin{array}{c}\text { Sangat } \\
\text { Rendah }\end{array}$ \\
\hline
\end{tabular}

2. Deskripsi Kompetensi Pengetahuan Siswa per Sub Indikator Berpkir p mbelajarán materi konflik sosial dengan midel problem based learning (kelas Kritis Hasil kompetensi pengetahuan sisw pe. Cpembelajaran langsung (kelas kontrol). sub indikator berpikir kritis div nat pay Dimana perbandingan presentase hasil post-test yang dikerjakan oleh siswa post-test yang diperoleh dapat dilihat pada menunjukan bahwa ter ja di poningkatan tabel berikut.

kompetensi pengethun iswa pada

Tabel 3. Per andingan Presentase Hasil Kompetensi Pengetahuan Siswa per Sub Indikator Berpikir Kritis Pada Kelas Eksperimen dan Kelas Kontrol

\begin{tabular}{|l|c|c|c|c|}
\hline \multirow{2}{*}{ Sub Indikator } & \multicolumn{2}{c|}{ Kelas Eksperimen } & \multicolumn{2}{c|}{ Kelas Kontrol } \\
\cline { 2 - 5 } & Presentase & Kriteria & Presentase & Kriteria \\
\hline Memfokuskan pertanyaan & $97,5 \%$ & Sangat Tinggi & $68,3 \%$ & Sedang \\
\hline Menganalisis argumen & $81,5 \%$ & Tinggi & $43,3 \%$ & Sangat Rendah \\
\hline $\begin{array}{l}\text { Mengobservasi dan } \\
\text { Mempertimbangkan Hasil Observasi }\end{array}$ & $97 \%$ & Sangat Tinggi & $64,4 \%$ & Rendah \\
\hline $\begin{array}{l}\text { Melakukan dan Mempertimbangkan } \\
\text { Hasil Induksi dan Deduksi }\end{array}$ & $86 \%$ & Tinggi & $36,7 \%$ & Sangat Rendah \\
\hline $\begin{array}{l}\text { Membuat dan Mempertimbangkan } \\
\text { Hasil Keputusan }\end{array}$ & $82 \%$ & Tinggi & $37,5 \%$ & Sangat Rendah \\
\hline
\end{tabular}




\section{Deskripsi Hasil Kompetensi}

\section{Pengetahuan Siswa Secara Klasikal}

Keseluruhan pembelajaran yang dilakukan, hasil komptensi pengetahuan siswa pada materi konflik sosial kelas eksperimen setelah mengikuti pembelajaran model problem based learning mengalami peningkatan dibandingkan kelas kontrol setelah mengikuti pembelajaran dengan model pembelajaran langsung di kelas. Hal ini dapat dilihat dari perbandingan presentase berpikir kritis secara klasikal kelas eksperimen dan kelas kontrol yang ditunjukan pada tabel berikut.

Tabel 4. Perbandingan Presentase Hasil Kompetensi Pengetahuan Siswa Secara Klasikal Pada Kelas Eksperimen dan Kelas Kontrol

\begin{tabular}{|l|l|c|c|c|}
\hline \multirow{2}{*}{ No. } & \multirow{2}{*}{ Kelompok } & \multicolumn{2}{|c|}{ Post-Test } & \multirow{2}{*}{$\begin{array}{c}\text { Peningkatan } \\
(\%)\end{array}$} \\
\cline { 3 - 4 } & & Presentase & Kriteria & \multirow{2}{*}{$44,8 \%$} \\
\hline 1. & Eksperimen & $90,2 \%$ & Sangat Tinggi & \\
\hline 2. & Kontrol & $52,4 \%$ & Rendah & \\
\hline
\end{tabular}

\section{B. Analisis Data Ketrampilan Berpikir} berpikir kritis sang dil kukan pada saat Kritis Siswa

Penilaian ketrampilan berpikir kritis siswa pembelajaran rent jukan bahwa terjadi dilakukan dengan menggunakan angket yang mengacu pada aspek yang diamati peningratan kecampilan berpikir kritis sicwa pada pembelajaran materi konflik s sial dengan model problem based berdasarkan indikator dan sub indikator zarning menggunakan cara pengambilan berpikir kritis untuk mengamati setiap can data di lapangan dan diskusi kelompok berpikir siswa tentang konflik so $\mathrm{Na}$ y.ng (kelas eksperimen) dibandingkan dengan terjadi pada saat mengamb data di model pembelajaran langsung (kelas lapangan dan mempresen asikan hasil data kontrol). Dimana perbandingan presentase yang diperoleh saat discosi di keas. asil yang diperoleh dapat dilihat pada Hasil ketrampilan pikir kritis siswa tabel berikut.

berdasarkan indikator dan sub indikator

Tabel 5. Perbandingan Presentase Hasil Ketrampilan Berpikir Kritis Siswa Pada Kelas Eksperimen dan Kelas Kontrol

\begin{tabular}{|c|c|c|c|c|}
\hline \multirow{2}{*}{ Inikator } & \multirow{2}{*}{ Sub Indikator } & \multicolumn{2}{|c|}{ Presentase } & \multirow{2}{*}{ Peningkatan } \\
\hline & & Eksperimen & Kontrol & \\
\hline \multirow{2}{*}{$\begin{array}{c}\text { Memberikan penjelasan } \\
\text { sederhana }\end{array}$} & $\begin{array}{l}\text { a. Memfokuskan } \\
\text { pertanyaan. }\end{array}$ & \multirow[t]{2}{*}{88,8} & \multirow[t]{2}{*}{58,8} & \multirow[t]{2}{*}{$30 \%$} \\
\hline & b. Menganalisis argumen. & & & \\
\hline $\begin{array}{c}\text { Membangun ketrampilan } \\
\text { dasar }\end{array}$ & $\begin{array}{l}\text { Mengobservasi dan } \\
\text { mempertimbangkan hasil } \\
\text { observasi. }\end{array}$ & 92,4 & 62,2 & $30,2 \%$ \\
\hline \multirow[t]{2}{*}{ Membuat kesimpulan. } & $\begin{array}{l}\text { a. Melakukan dan } \\
\text { mempertimbangkan } \\
\text { hasil induksi dan } \\
\text { deduksi. }\end{array}$ & \multirow[t]{2}{*}{98,4} & \multirow[t]{2}{*}{80,2} & \multirow[t]{2}{*}{$18,2 \%$} \\
\hline & $\begin{array}{l}\text { b. Membuat dan } \\
\text { mempertimbangkan } \\
\text { hasil keputusan. }\end{array}$ & & & \\
\hline
\end{tabular}




\section{Deskripsi Hasil Uji Hipotesis}

Hasil uji validitas menunjukkan bahwa nilai korelasi soal tampak melebihi 0,30 dengan signifikansinya kurang dari 5\% yang dapat dikatakan soal pada variabel berpikir kritis adalah valid, uji reliabilitas menunjukkan bahwa 0,967 termasuk kategori sangat kuat atau sangat tinggi dengan koefisien nilai reliabilitas $0,80-$ 1,00, dan uji tingkat kesukaran soal yang tertinggi adalah 0,28 dengan kategori indeks kesukaran soalnya $0,00-0,30$.

Uji selanjutnya yaitu uji beda rata-rata, terlihat nilai $t_{\text {hitung }}$ yang dihasilkan sebesar 5,637 dengan tingkat signifikansi (sig)

\section{KESIMPULAN}

Berdasarkan hasil penelitian dan analisis deskriptif diperoleh bahwa pembel, arap model problem based learning dengary strategi belajar diskusi kelasnefektif youk meningkatkan berpikir k sis siswa, kesimpulan ini did arkg n pa beberapa hal, yaitu: (1) Pembelajaran yang dikelola oleh guru tergolong baik, (2) Siswa melakukan aktivitas tergolong aktif, (3) Respon siswa terhadap pembelajaran positif, (4) Ketuntasan hasil belajar tercapai.

Berdasarkan hasil analisis inferensial diperoleh kesimpulan bahwa "ada kurang dari 5\% yaitu 0,000 sedangkan harga t tabel $(0,05$, df 36$)=1,688$. dengan demikian $\mathrm{t}_{\text {hitung }}=5,637 \geq \mathrm{t}$ tabel $(0,05$, df 36) $=1,688$.

Hal ini berarti bahwa ada perbedaan ratarata post-test berpikir kritis siswa pada pembelajaran dengan model problem based learning lebih tinggi dibandingkan pembelajaran dengan metode ceramah. hipotesis penelitian ini "Ada perbedaan berpikir kritis pada kelas yang menerapkan pembelajaran den an model problem based learning dengar kergs yang menerapkan pembelaivan den san metode ceramah" teruji sebunarannya.

purbed aan berpikir kritis pada kelas yang ne nerapkan pembelajaran model problem based learning dengan strategi belajar diskusi kelas dengan kelas yang menerapkan pembelajaran metode ceramah" teruji kebenarannya. Hal ini ditunjukkan oleh nilai sig. $0,000 \leq 0,05$ dan $t_{\text {hitung }}(5,637) \geq 1,688$, ini berarrti bahwa ada perbedaan rata-rata post-test berpikir kritis siswa pada pembelajaran model problem based learning strategi belajar diskusi kelas lebih baik dibandingkan pembelajaran metode ceramah dalam hal ini meningkatkan berpikir kritis siswa. 


\section{DAFTAR PUSTAKA}

Arikunto. (1984). Dasar-Dasar Evaluasi Pendidikan. Jakarta: Bina Aksara.

Arthur, A. S. (1986). Conflict and Cohesion. Dalam The Journal of Conflict Resolution. Vol. 20. (1),143-155. [Online]. Tersedia: http://infotrac.galegroup.com [28 November 2016]

Christoper, R. D. (2009). Reconciliation and Revitalization: The Resurgence of Tradition in Postconflict Tobelo, North Maluku, Eastern Indonesia. Dalam The Journal of Asian Studies. Vol. 68. (4),1077-1087. [Online]. Tersedia: http://infotrac.galegroup.com [28 November 2016]

Claire, M. and Betsy, P. (2001). Assessing the Effectiveness of Problem-Based Learning in Higher Education: Lessons From the Literature. Dalam Education Journal. Vol. 15. (3),101-112. [Online] Tersedia: http://journals.cambridge.org/action/login [28 November 2016]

Djamrah. (2002). Psikologi Belajar. Jakarta: Rineka Cipta.

Douglas, P. and Bjorkqvist, K. (1999). Culture and Conf / Resol-cion/Culture Variation and Resolution: Alternatives to Violence. Dalam Journa America Anthropologist. Vol. 101. (4),870-872. [Online]. Tersedia: htt ://infotrac.galegroup.com [28 November 2016]

Gleiser and David. (2005). Moral Conflict: Whe Sycial Worlds Collide. Dalam International Journal of Conflict Managenelt. Tr. 10. (3),300-312. [Online]. Tersedia: http://infotrac.galegroup.com [2 Novornber 2016]

Jerry, J. V. (2007). Clarifying Interpersonal and Social Values Conflict Among Recreationists. Dala A Journal of Lesisure Research. Vol. 39. (1),182-195. [Online]. Tersedia: http://inrotrogå group.com [28 November 2016]

Jordan and Thomas. (1 Confronting Conflict. A First Aid Kit for Handing Conflict. Dalam Internaticnal Journal of Conflict Managament. Vol. 10. (3),304-315. [Online]. Tersedia: http://infotrac.galegroup.com [28 November 2016]

Joseph, M. F. (1974). Continuities In the Theory of Violence. Dalam The Journal of Conflict Resolution. Vol. 18. (1),117-127. [Online]. Tersedia: http://infotrac.galegroup.com [28 November 2016]

Kemdikbud. (2013). Ilmu Pengetahuan Sosial Buku Guru Kelas VII SMP. Jakarta: Badan Pengembangan Sumber Daya Manusia Pendidikan Dan Kebudayaan Dan Penjaminan Mutu Pendidikan.

Pruitt dan Jeffrey. (2004). Teori Konflik Sosial. Pustaka pelajar: Yogyakarta.

Sarah, W. K. and Ruth, W. T. (2016). A Critical Analysis On the Transition Dynamics and Student Transition Adjustment From Preschool to Lower Primary School in Kenya. 
Dalam International Journal of Education and Research. Vol. 4 (2),115-152. [Online]. Tersedia: http://journals.cambridge.org/action/login [28 November 2016]

Slameto. (2010). Belajar dan Faktor-faktor yang Mempengaruhinya. Jakarta: PT. Rineka Cipta.

Suroso. (2015). Penerapan Model Pembelajaran Problem Based Learning Untuk Meningkatkan Hasil Belajar IPS Siswa Kelas VIII C SMP Negeri 1 Jatinegara Kabupaten Tegal. Dalam Jurnal Pendidikan IPS. Vol. 2. (2), 201-211. [Online]. Tersedia: http://ejournal.upi.edu [21 November 2016]

Sudjana. (2005). Penilaian Hasil Proses Belajar Mengajar. Bandung: PT. Remaja Rosdakarya.

Valdes, R. B. (2009). Students and Tutors Social Representations of Assessment in ProblemBased Learning Tutorials Supporting Change. Dalam Edug atro Journal. Vol. 10. (4),78-88. Tersedia: http://journals.cambridge.org/action/logn__28 November 2016]

Wahab, A. A. (2009). Metode Dan Model-Model Mengajar Pengetahuan Sosial. Bandung: Alfabeta.

Winkel. (1984). Psikologi Pendidikan Dan Evalua îelajar Jakarta: Gramedia rosdakarya.

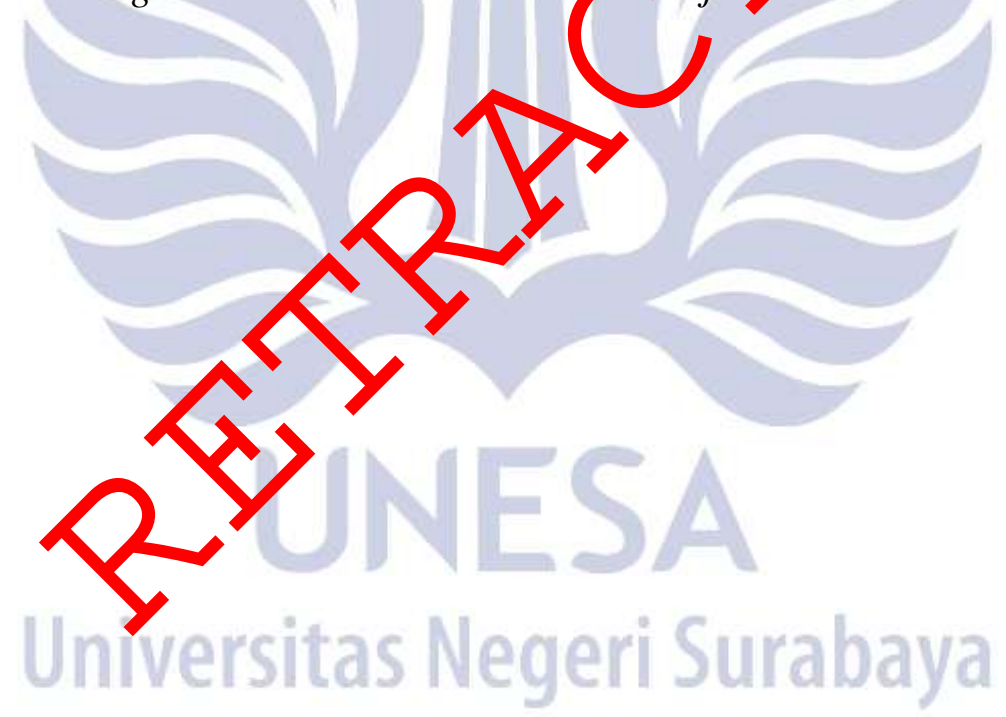

